\title{
CONTRIBUIÇÕES DA MISSÃO MILITAR FRANCESA PARA O DESENVOLVIMENTO DO DESPORTO NO EXÉRCITO BRASILEIRO.
}

\author{
(Comemoração aos 100 anos do início da orientação daquela Missão) \\ Primeira parte
}

\author{
THE CONTRIBUTION OF THE MILITARY FRENCH MISSION TO THE \\ DEVELOPMENT OF SPORTS IN THE BRAZILIAN ARMY
}

(100 Year-celebration on the beginning of orientation in that mission) Part one

André Morgado Ribeiro ${ }^{1}$

\begin{abstract}
Resumo: O presente artigo foi idealizado no intuito de descrever as importantes contribuições da Missão Militar francesa no campo das práticas esportivas, na promoção do aprimoramento do condicionamento físico e a difusão, no público civil, de sua importância para a saúde e a disciplina no Exército Brasileiro. Dessa forma, primeiramente abordou-se a importância do treinamento físico militar no Brasil e suas influências. Em seguida, foi realizada uma pesquisa sobre os contextos históricos brasileiros da Educação Física e o Exército, sob o enfoque da influência francesa. Por fim, tratou-se dos esportes e das atividades físicas como instrumentos da formação cívica e do desenvolvimento da disciplina entre seus praticantes.
\end{abstract}

Palavras-chaves: Exército. Educação Física. Missão Militar francesa.

\begin{abstract}
The present study has the purpose of describing the important contributions of the French Military Mission to sports practice, to the promotion of physical condition improvement and to the diffusion, among civilians, of its importance to health and discipline in the Brazilian Army. Therefore, the importance of military physical training in Brazil and its influence were discussed. Following, a research on the historical background about the relationship between Physical Education and the Army was carried out, with great emphasis on the French influence. Then, sports and physical activities as instruments for civic formation and the development of discipline among people were significantly treated as well. Keywords: Army. Physical Education. French Military Mission.
\end{abstract}

Aceito em 11/09/2009 - Rev. Educ. Fís. 2009 - 40-47. Rio de Janeiro - RJ - Brasil

\section{INTRODUÇÃO}

As origens do Exército brasileiro remontam à primeira metade do século XVII, quando brancos, negros e índios do nordeste se uniram para expulsar o invasor holandês. Nessa ocasião foi utilizado, pela primeira vez, no Brasil, o termo pátria. O patrimônio imaterial da Força terrestre tem sua gênese em Guararapes. Diferentes culturas interagiram e se fundiram por meio de inúmeros fatores entre os quais destacamos os traços biológicos transmitidos, a transmissão de conhecimentos e as criações intelectual, artística e profissional. Dessa interação surgiu uma nova identidade, uma rica e universal cultura que se consolida e prospera ao longo de mais de trezentos anos (1).

Nessa fusão de raças está a história do nosso Exército, instituição que se preocupa com a valorização do homem, agente criador que se manifesta em diversas atividades culturais da pátria.

O Exército tem sido no Brasil muito mais do que uma simples instituição armada prevista na organização do estado para desempenhar sua destinação constitucional: a defesa da pátria assegurando a preservação da soberania nacional, na garantia dos poderes 
constitucionais, na manutenção da lei e da ordem e de operações humanitárias e de cooperação internacional.

Neste artigo especificamente, há de se ressaltar o importante papel do Exército na evolução e difusão dos esportes e, principalmente, da formação dos recursos humanos em Educação Física, no Brasil, como fator incontestável na valorização do homem em diversas partes do território nacional.

Ao longo da história muitas foram as influências sofridas pela Instituição. Nos séculos de 1920 e 1930, integrou-se na Força Terrestre uma Missão Militar Francesa composta de oficiais, subalternos e civis assemelhados. O acordo dos Franceses para servir ao Exército deveu-se por duas razões: o despreparo do Exército e a evolução da $1^{\text {a }}$ Grande Guerra, na qual a França foi vitoriosa. A Missão Militar Francesa contribuiu para que ocorressem expressivas mudanças na área esportiva e de treinamento físico no Exército brasileiro, com relevantes reflexos na História do Brasil.

Apesar de tudo que foi descrito acima, permanece a necessidade de mais informações para a compreensão do exercício do papel da Missão Militar Francesa no Exército brasileiro e sua contribuição para a interpretação do Esporte nacional. É evidente que esta interpretação sempre foi relacionada aos contextos históricos de cada época.

\section{A IMPORTÂNCIA DO TREINAMENTO FÍSICO MILITAR NO BRASIL}

A evolução do Treinamento Físico Militar também está associada à evolução da educação física no Brasil. Desde meados do século XIX, o militarismo foi o principal difusor de influências importantes para o desenvolvimento e disciplinarização da Educação Física. Em diversos momentos do século $X X$, militares aforam responsáveis em trazer ao Brasil as mais modernas concepções acerca da Educação Física e do treinamento presentes no mundo e disseminar sua prática e realizar adaptações para sua assimilação no país ${ }^{(1,2,3,4)}$.
FIGURA 1

TFM DE ALUNOS DA EEFE NA DÉCADA DE 1940

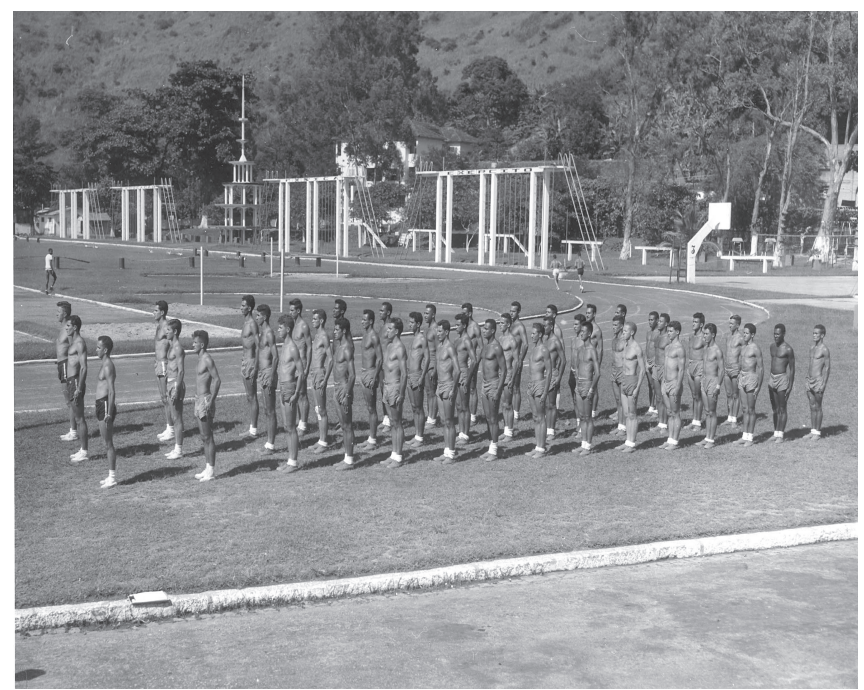

Foto do arquivo digital: Museu do Desporto do Exército

A evolução do Treinamento Físico Militar (TFM) no Brasil é comumente dividida em sete fases: primórdios; a fase da educação física militar; a fase da influência francesa, a fase da influência norteamericana; a fase da Escola Brasileira; a Era Cooper e a década de 1980. É importante ressaltar que as diferentes fases acompanham a influência acerca da Educação Física no Brasil ${ }^{(1,2)}$.

\section{a) Primórdios}

Até o período da independência, não havia sistematicidade na pratica de atividades físicas que pudessem ser comparadas aos manuais de educação que existiam na Europa neste período. Somente em 1828, foi publicado o primeiro manual de Educação Física, intitulado "Educação Física Moral dos Meninos", de Joaquim Jerônimo Serpa. Neste período a educação física estava relacionada à educação de crianças e jovens e não possuía conotação militar ${ }^{(1,2)}$.

\section{b) Educação Física Militar}

Em 1858, foi sacramentado o primeiro documento (decreto no 2116) abordando o treinamento físico para militares, que estabelecia cursos de esgrima e natação como práticas escolares nos cursos de Infantaria e Cavalaria da Escola Militar. Na segunda metade do século XIX, o Exército Brasileiro é a primeira Instituição a sistematizar o treinamento físico como instrução militar no continente americano. Em 1860 , se inicia o primeiro treinamento específico para 
praças, composto por cursos de natação, ginástica e esgrima ${ }^{(1,2)}$.

Em 1874, após a Guerra do Paraguai, o decreto no 5529, previa que dentre as disciplinas do curso teórico da Escola Preparatória, anexa à Escola Militar, deveriam ser praticados a ginástica, a esgrima e a natação. Este regulamento destacava o papel do ensino da educação física na prática militar. Também foi prevista a orientação especializada do treinamento e detalhes que regulavam a aplicação dos cursos. Os regulamentos posteriores (1889, 1898, 1905, 1914, 1918 e 1919) conservam as exigências presentes no regulamento de $1874^{(1,2)}$.

Também em meados do século XIX, no âmbito da Escola Militar surgiam inúmeros cadetes que praticavam esportes náuticos. Este aspecto foi reflexo das aulas de natação e da proximidade geográfica da Escola com o mar. Os cadetes organizaram clubes e através deles obtinham recursos para a prática da canoagem. Essas práticas estavam intrinsecamente relacionadas ao lazer.

Em 1905 foi publicado o primeiro livro com prescrições acerca do treinamento físico especificamente militar, de autoria do Capitão de Artilharia Domingos Nascimento. O autor era seguidor do método francês deDemeny. Nestemesmo período, há um debate público acerca da educação física e do desempenho do militar em combate. Para muitos, o insucesso da tropa na Guerra de Canudos se devia às diferentes correntes de pensamento que geravam polêmicas, evidenciando uma preocupação crescente com o melhor adestramento físico da tropa e a má aptidão física dos soldados ${ }^{(1,2)}$.

\section{FIGURA 1}

TFM DE ALUNOS DA EEFE NA DÉCADA DE 1940

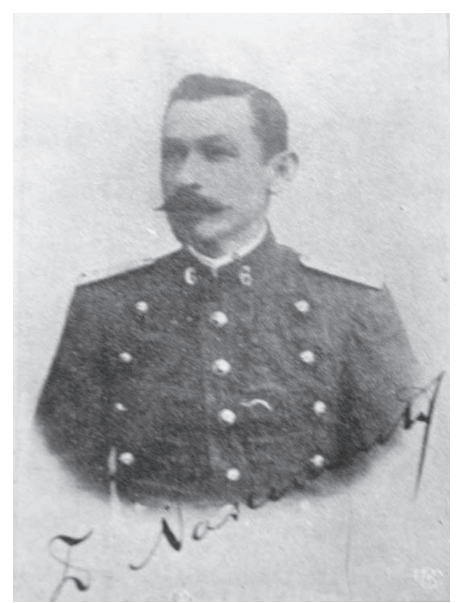

Foto do arquivo digital: Museu do Desporto do Exército

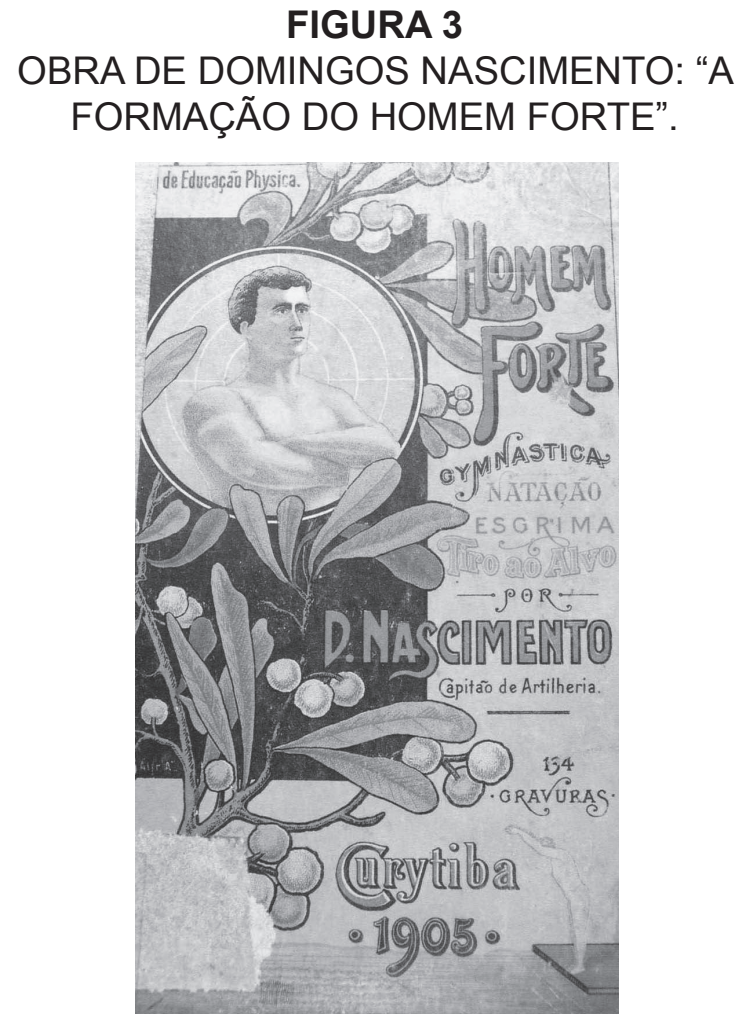

Foto do arquivo digital: Museu do Desporto do Exército

A partir desse debate as instituições militares existentes buscam aprimorar a prática de atividades físicas voltada para a rotina militar. Visando a modernização da Força Terrestre, trinta e quatro oficiais, divididos em três grupos, estagiaram entre os anos de 1905 a 1912, nas organizações militares da Alemanha, importando as práticas calistênicas e o pensamento alemão. Em 1909, foi fundada a primeira Escola de Educação Física Militar no Brasil, na então Força Pública de São Paulo. A origem dessa escola está vinculada à atuação da missão francesa da Escola Militar de Ginástica de Joiville-Le-Pont e suas ações no Brasil. Nesta escola foram diplomados os primeiros mestres em educação física do país ${ }^{(1,2)}$.

\section{c) A influência francesa}

O principal evento deste período foi a fundação da Escola de Educação Física do Exército (EsEFEx), em 1933. A criação da escola representa a evolução da educação física no âmbito militar e visa suprir a necessidade de formação e pesquisa para o desenvolvimento do Treinamento Físico Militar no Brasil (1,2). 
FIGURA 4

GALPÃO ONDE FUNCIONAVAA

EsEFEx, EM 1931.

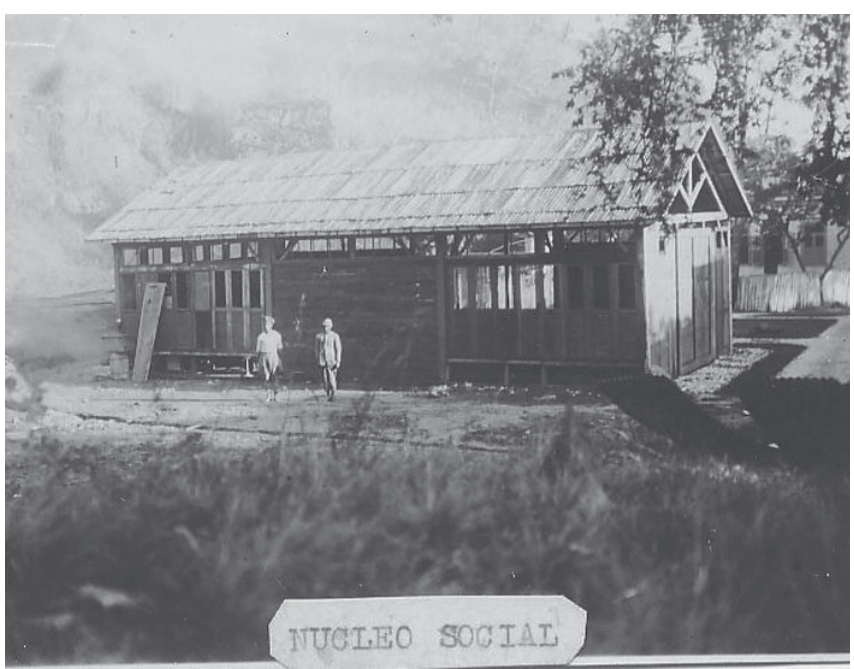

Foto do arquivo digital: Museu do Desporto do Exército

Antes da fundação da Escola, a I Guerra Mundial representa um marco para o deslocamento da discussão acerca do treinamento físico militar em âmbito mundial. No início da década de 1920, uma comitiva francesa composta por trinta oficiais chefiados pelo General Gamelin, assume o controle da instrução militar em diversos níveis. A partir de então, o modelo francês foi difundido enquanto paradigma de organização do Exército ${ }^{(1,2)}$.

Neste período, a Escola Francesa já havia desenvolvido um método próprio, já testado na I Grande Guerra. Aquele sistema considerava como fundamental o funcionamento do coração e pulmões, a reação destes órgãos ao esforço físico continuado e os reflexos daquele esforço sobre o corpo humano ${ }^{(1,2)}$.

O tenente da marinha francesa, Georges Hébert, elaborou o Método Natural - conjunto de procedimentos para exercitar o corpo. Levou em conta as seguintes idéias: retorno à natureza, a importância do sol e das atividades ao ar livre e seus movimentos ao natural. Tais idéias influenciaram na criação do chamado método Francês denominado "Règlement General D’Éducation Physique" $(5,6)$.

Data de 1926 a publicação do primeiro Manual de Educação Física do Exército, de autoria do Capitão João Batista Leite e do Ten.
FIGURA 5

TREINAMENTO FÍSICO MILITAR EM 1934.

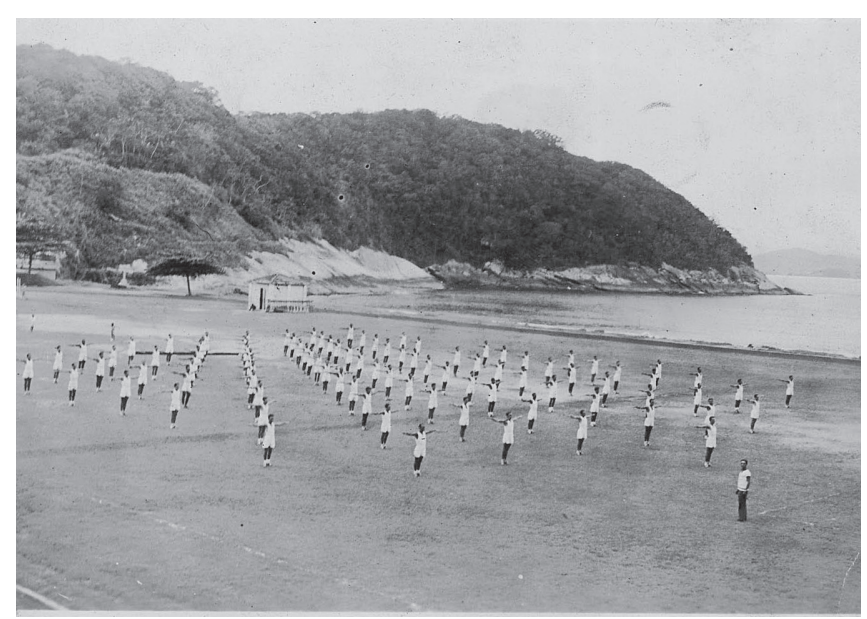

Foto do arquivo digital: Museu do Desporto do Exército

Jair Jordão Ramos. Este manual traduzia os princípios e as práticas da Escola Francesa.

d) A Influência norte-americana

O êxito das operações militares norteamericanas realizadas na II Guerra Mundial põe em evidência o treinamento físico militar deste país (calistenia). Em contraposição com o método francês, mais direcionado à organização do ensino da educação física e ao desenvolvimento de pesquisa acerca do tema, o método norte-americano era centrado em treinamento físico de curto prazo e exercícios afins as atividades militares ${ }^{(1,2)}$.

No início da II Guerra, havia o consenso de que a influência francesa havia produzido um sistema de ensino adequado e um exército disciplinado, mas defasado, em termos práticos, no componente treinamento físico. Sabia-se também que as inovações em termos de armamento e a necessidade de adaptação às novas condições de combate exigiam maior aptidão física do combatente. No Brasil, o treinamento físico era orientado pela ginástica de fundo escolar. Não se praticava exercícios específicos para o combate. Não havia, nos corpos de tropa, a continuidade do treinamento físico nem a percepção de sua importância para o combate ${ }^{(1,2)}$.

A fim de mudar este quadro, em 1943 foi organizada a Força Expedicionária Brasileira, que enviou mais de 300 militares para realizar cursos junto ao Exército dos Estados Unidos 
da América (EUA). Após a atuação da Força Terrestre na Itália, havia a percepção de que nossos soldados não estavam preparados para aquele tipo de combate. Os cursos realizados nos EUA e a experiência brasileira na II Guerra mudaram as concepções acerca da relação entre treinamento físico militar e combate ${ }^{(1,2)}$.

Em 1947, a EsEFEx cria o Manual de Educação Física, de marcada influência francesa e já considerado obsoleto para as necessidades da época.

\section{e) A Escola Brasileira}

Embora tenha sofrido inúmeras influências norte-americanas na II Guerra, através do uso de manuais daquele exército e do envio de pessoal para treinamento naquele país, o Exército brasileiro manteve sua organização de antes da Guerra. Neste período, o que houve foi a síntese e adaptação das principais correntes que influenciaram a organização desta instituição, a influência alemã, francesa e norte-americana. A principal característica da escola brasileira é o ecletismo ${ }^{(1,2)}$.

O Manual de Campanha Básico, conhecido como Manual para Treinamento Físico Militar, editado em 1958, é o primeiro marco do método brasileiro. Em primeiro lugar, estava preconizada a moderna idéia de educação integral militar, pois o objetivo do treinamento era “... a preparação do soldado para vencer a guerra. Assim agindo, coopera, também, no desenvolvimento de certas habilidades técnicas, no estabelecimento do equilíbrio emocional e no apuro de suas qualidades morais". Este manual incorporava a ênfase ao preparo físico à base de exercícios intensos e da sobrecarga, de base norte-americana e exercícios tipicamente de base francesa (saltar, pular, correr, levantar, transportar e lutar) ${ }^{(1,2)}$.

Em 1962, é editado outro Manual, o de Campanha Básico - Instrução Individual Educação Física Militar, focado no método norte-americano (calistenia), adaptado ao método Wood/Skarstrom, aplicado pela Associação Cristã de Moços (ACM) em diversas partes do mundo. Devido a sua universalidade, este método era mais adequado aos fins civis. Embora este manual introduzisse novos elementos, não adotou o princípio da sobrecarga; era uma ginástica cotidiana, mais específica aos civis do que ao preparo para o combate ${ }^{(1,2)}$.

Durante os anos sessenta, o Treinamento Físico Militar passou por um período de afirmação, onde se chocavam os feitos no campo esportivo com os efeitos da aplicação do Manual nos corpos de tropa ${ }^{(1,2)}$.

Devido aos métodos desenvolvidos pela EsEFEx, há destaque dos esportes militares, como: o pentatlo militar, o tiro e o pentatlo moderno. Neste campo, houve grandes êxitos, mas o adestramento físico da tropa ainda se mostrava deficiente e sem especificidade.

\section{f) Era Cooper}

No final da década de 1960, o Capitão Cláudio Pecego Moraes Coutinho, instrutor da EsEFEX, conheceu o Dr. Kenneth Cooper, major da Força Aérea americana, durante estágio realizado na França. Logo após foi realizar estágio no Centro de Treinamento Físico da USAF (United States Air Force). Ao retornar ao Brasil, em 1970, o Capitão Coutinho e uma equipe da EsEFEx foram chamados para realizar o preparo físico da seleção brasileira de futebol. A vitória do Brasil na competição deu projeção internacional a este método e facilitou sua incorporação pelo Exército brasileiro ${ }^{(1,2)}$.

\section{FIGURA 6}

CAPITÃO CLAUDIO COUTINHO.

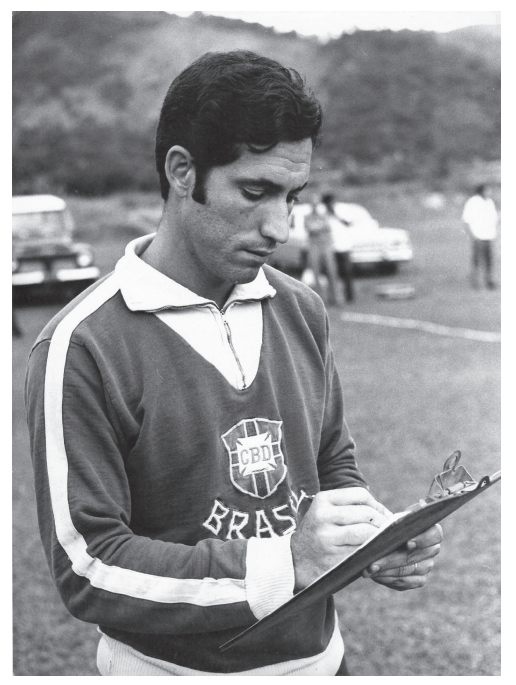

Foto do arquivo digital: Museu do Desporto do Exército 


\section{FIGURA 7}

TREINAMENTO FÍSICO DA SELEÇÃO NOS PREPARATIVOS PARAA COPA DE 1970

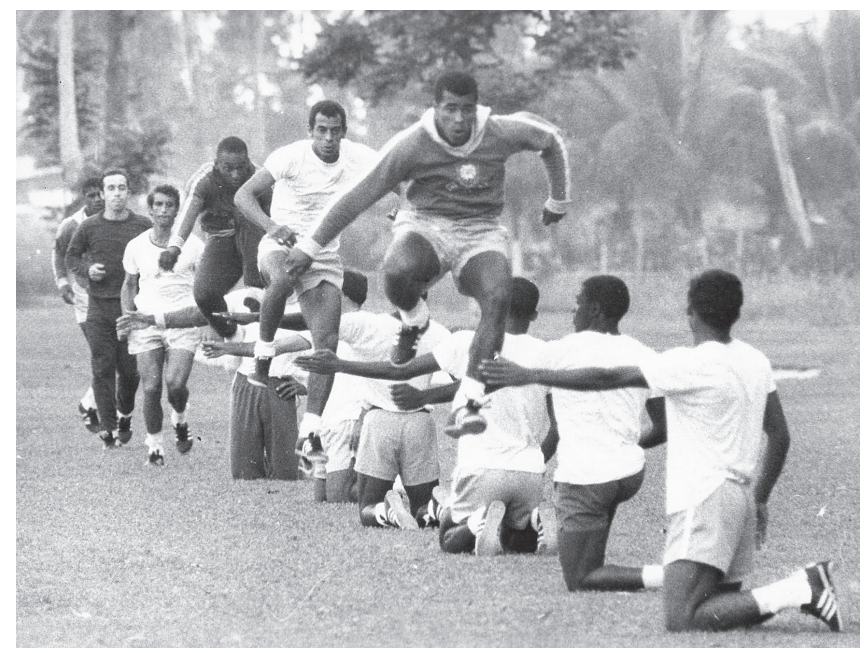

Foto do arquivo digital: Museu do Desporto do Exército

O Manual de Campanha de 1973 (C21-20) é orientado pelo método Cooper adaptado ( ) pela EsEFEx, trazendo para o treinamento militar os conceitos de treinamento orgânico (aeróbico) e treinamento neuromuscular. Em termos práticos, houve um aumento das corridas e a obrigatoriedade de testes físicos regulares. Em princípio, as modificações receberam diversas críticas, pois achava-se que as exigências não correspondiam à realidade brasileira ${ }^{(1,2)}$.

Em 1975, a $2^{a}$ edição do Manual de 1973 trazia o conceito de aptidão física e incluiu a divisão da tropa em dois grupamentos etários (até 35 anos e de 35 a 45 anos), com a organização de um plano de treinamento de quarenta semanas, visando padronizar as seqüências e a carga das sessões. A referida edição representa a reorientação do Treinamento Físico Militar aos mais modernos conceitos da ciência esportiva da época ${ }^{(1,2)}$.

Este período significou o ápice da EsEFEx, que desde sua fundação representou a vanguarda do ensino e pesquisa da Educação Física no Brasil. Suas instalações eram utilizadas para a realização de treinamentos (civis e militares), seminários e simpósios. Durante a década de 1960, foi um dos pólos de disseminação da prática de exercícios pela sociedade civil. Além disso, as mudanças tiveram repercussão positiva no Treinamento Físico Militar da Força Terrestre, pois notava-se melhor aptidão dos militares e também observava-se a continuidade da prática de exercícios em instituições militares ${ }^{(1,2)}$.

Embora tenha participado do processo de disseminação da prática de exercícios físicos, a proliferação de faculdades de educação física, clubes e academias (final da década de 1970), que representavam a popularização da prática, contribuíram para deslocar o papel de vanguarda da EsEFEx. A prática de exercícios físicos exigia cada vez mais investimento em formação de pessoal especializado, instalações específicas e diálogo com o campo acadêmico, tarefas que deixaram de acontecer e a Escola perdeu, gradativamente, sua hegemonia no campo ${ }^{(1,2)}$.

Neste período, as equipes esportivas militares deixaram de participar de importantes eventos internacionais. Devido ao distanciamento com o campo acadêmico e a falta de apoio e investimentos em pessoal e infra-estrutura, o TFM deixou de ser acompanhando adequadamente. Com isso, o conceito de Teste de Avaliação Física (TAF), incorporado no manual de 1973, foi confundido com o próprio treinamento e deixou de servir a seu propósito fundamental, que é avaliar a aptidão física do militar ativo. A partir de então, há profundo entrelaçamento e confusão entre o treinamento físico militar e o teste de avaliação física $^{(1,2)}$.

\section{g) Década de 1980}

Com todos esses desdobramentos, em 1979 a EsEFEx iniciou os estudos, com pesquisas de levantamentos para realizar um novo Manual de Treinamento Físico, finalizado em 1980 e implementado em 1981, chamado de C 20-20. As principais alterações do manual foram: a extinção de algumas ginásticas, padronização do aquecimento (preparatória); redefinição de conceitos fisiológicos; e, reorganização das faixas etárias (até 35 anos, de 35 a 45 anos e acima de 45 anos). No que se refere ao Teste de Avaliação Física, as modificações foram discretas, sendo a mais importante a adoção do controle fisiológico. Também houve a realização de um plano de treinamento de vinte semanas para militares que haviam se afastado das atividades físicas ${ }^{(1,2)}$.

Em decorrência, a 17 de dezembro de 1981, foi fundado o Esporte Clube São João (ECSJ), com o objetivo da prática da atividade física através da iniciação esportiva e do treinamento 
de atletas. O ECSJ funciona como fomento a Escola e tem como premissa divulgar as mais diversas modalidades do esporte, iniciando e aperfeiçoando crianças e adultos. Localizado dentro da Fortaleza de São João e valendo-se dos equipamentos e das instalações da EsEFEx, o clube é uma entidade civil, sem fins lucrativos tendo como professores o corpo docente da Escola.

Apesar de representar a adequação do Treinamento Físico Militar às exigências contemporâneas, o Estado Maior do Exército (EME), através da portaria $n^{\circ} 73$, de 1983, estabeleceu como índices de aptidão física satisfatório, as pontuações situadas na menção insuficiente (I) do C 20-20. No ano seguinte, o EME voltaria a modificar os parâmetros da aptidão física, desta vez correspondendo a menção regular (R). Essas transformações foram realizadas sem consulta prévia à EsEFEx e representaram um retrocesso no trabalho que vinha sendo realizado ao longo de anos na área de Treinamento Físico Militar, contribuindo para a dispersão da atividade física nos corpos de tropa e total descrédito ${ }^{(1,2)}$.

No mesmo ano, 1984, o EME ficou responsável por realizar um projeto para construção de um grupo de estudos para estabelecer um novo TAF. Este grupo foi chamado de Projeto TAF. Embora em diversos momentos tenha realizado portarias que aproximavam os índices de aptidão adotados com o padrão sistematizado pelo C 20-20, este projeto foi responsável pela dispersão da prática do treinamento e pelo descrédito do teste físico $(1,2)$

Em março de 1986, através da portaria 014EME, surgiu como primeira tentativa dentro da realidade, o aperfeiçoamento do TAF, ligado ao Sistema de Instrução Militar do Exército Brasileiro (SIMEB).

Somente em 1987, o EME determinou que a EsEFEx realizasse um novo manual. Durante os anos seguintes foram realizados teste e em 1990 o documento foi finalizado.

\section{CONCLUSÃO}

Apartir desseestudo, pode-se percebero quão significativa e variada é a contribuição da CDE, do IPCFEx e da EsEFEx e, conseqüentemente, do Exército Brasileiro para o esporte nacional. Tal contribuição mostrou-se sempre adequada à situação política e à necessidade demonstradas pelo corpo esportivo nacional.

Imbuído do espírito de pioneirismo e sempre buscando a excelência, incentivado pela Missão Militar Francesa, procurou o intercâmbio com outros países.

O Exército inicia o estímulo à Educação Física nos primórdios do século passado com a criação da Liga Militar de Futebol passando a denominar-se Liga de Sports do Exército, posteriormente conhecido como Comissão de Desportos do Exército. Não diferente foi a criação do Centro Militar de Educação Física, passando a ser chamado de Escola de Educação Física. Sua cooperação para o desenvolvimento do esporte nacional é incansável. Nos atuais dias, desde a criação do Instituto de Pesquisa da Capacitação Física, coordena e executa projetos e trabalhos de pesquisas voltados para a operacionalidade da Força Terrestre e à saúde de seus integrantes, mantendo o compromisso com as ciências dos esportes.

Em alguns momentos, fez-se pioneiro, ao buscar a formação profissional, a organização de competições e o desenvolvimento e apresentação de novos métodos no campo da Educação Física. Em outros, mostrou-se capaz de buscar, junto à sociedade civil, os meios de manter-se em constante aperfeiçoamento e assegurar sua posição como centro de excelência no cenário esportivo nacional.

\section{REFERÊNCIAS BIBLIOGRÁFICAS}

1. Vieira MAO. Treinamento Físico Militar no exército Brasileiro. Monografia apresentada a Escola de Comando e Estado-Maior do Exército. Rio de Janeiro: 1989.

2. Dias RR. Treinamento Físico Militar: Análise da evolução, da avaliação e uma proposta de adequação às diferentes atividades do militar da força terrestre. Rio de Janeiro: 1995. Monografia apresentada a Escola de Comando e Estado-Maior do Exército.

3. Oliveira LL. FGV - CPDOC. A Era Vargas. Disponível em: http://www.cpdoc.fgv.br/nav_fatos_imagens/index. (04 jun. 2008) 
4. Soares CL. Educação física: raízes européias e Brasil. Campinas: Autores Associados. 1994.

5. Soeiro RSP, Cunha RSP. Evolução contextual do Esporte/Educação Física no período anterior à criação da Escola de Educação Física. Rio de Janeiro: Revista de Educação Física, 2003; 127:71-9.

6. Hébert G. Lê code de la force. Paris: Vuibert, 1911.

(A Missão Militar Francesa no Brasil, 1983, p.6)

1. Revista DaCultura 2008 (VII) ;, № 12 , Ed 2008;

2. autor, titulo obra, periódico com ano, nr revista, paginas ESTADO MAIOR DO EXÉRCITO. História do Exército Brasileiro. Perfil Militar de um Povo. Rio de Janeiro/ Brasília: EMFA, 1972. v.7.

FERREIRA NETO, A. A Pedagogia no Exército e na Escola: a educação física brasileira (1880-1950). Aracruz: Facha, 1999.

MELO, V. A. de. História da educação física e do esporte no Brasil: panorama e perspectivas. São Paulo: Ibrasa, 1999.

MELO, Victor Andrade de. Relação Teoria \& Prática e Formação profissional na Educação Física Brasileira: Apontamentos na história. Revista Motrivivência, Florianópolis, SC, n. ${ }^{\circ}$ 8, Ano 7, 1995, p103-115.

Escola Nacional de Educação Física e Desportos: uma possível História. Dissertação (Mestrado em Educação Física) Campinas: Unicamp, 1996.

O papel dos militares no desenvolvimento da formação profissional na educação física brasileira. Mimeo, 2000.

MOLINA, Antonio. Escola de Educação Física do Exército. Sua atuação em prol da Educação Física nacional. Revista de Educação Física. Rio de Janeiro, n.25, p. 5-7, ago. 1935.
RAMOS, Jair Jordão. Os exercícios físicos na história e na arte: do homem primitivo aos nossos dias. São Paulo: Ibrasa, 1982.

REVISTA DE EDUCAÇÃO FÍSICA. História do Departamento de Educação Física do Estado de São Paulo de 1931 a 1934. Rio de Janeiro: EsEFEx, n. 31, 1936-1937.

SOEIRO, Renato Souza Pinto \& TUBINO, Manoel José Gomes. A contribuição da Escola de Educação Física do Exército para o esporte nacional: 1933 a 2000. In: Fitness \& Performance Journal. ANO2, ED.6. 2003. Disponível em: http://www.sumarios.org/pdfs/587_2781.pdf . Acesso em: 04/06/08.

TAVARES, Aurélio de Lyra. Nosso Exército: essa grande escola. Rio de Janeiro: Biblioteca do Exército, 1985.

TUBINO, Manoel Gomes. Metodologia cientifica do treinamento desportivo. São Paulo: Ibrasa, 1984.

Educação física no Brasil. São Paulo: Ibrasa, 2007.

Dicionário enciclopédico Tubino do esporte. Rio de Janeiro: SENAC, 2007.

História da educação física no Brasil. São Paulo: Ibrasa, 2008.

Endereço para correspondência:

Avenida João Luís Alves s/nr - Urca - Rio de Janeiro - RJ CEP 22.291-090

Telefone: (21) 2586-2269 ou (21) 8585-3042

Fax:(21) 2295-5340

e-mail: andre.morgado@globo.com 